Human Development 1967;10:137

\title{
A Note on this Issue
}

We are pleased to devote the current issue of Human Development to the publication of a group of papers on "Naturalistic Methods in Psychological Research". The papers were originally presented as a symposium at the meetings of the American Psychological Association, New York, N.Y., September 4, 1966.

It may interest Human Development readers to know that the authors of these papers are currently expanding and rewriting them for publication in a book edited by Drs. Edwin P. Willems and Harold L. Raush, entitled Naturalistic Viewpoints in Psychological Research, to be published by Holt, Rinehart and Winston.

Editors

10 Human Development, Vol. 10, No. 3-4 (1967) 